\title{
Short communication: Comparison of the GreenFeed system with the sulfur hexafluoride tracer technique for measuring enteric methane emissions from dairy cows
}

\author{
A. N. Hristov, ${ }^{* 1}$ J. Oh, ${ }^{*}$ F. Giallongo, ${ }^{*}$ T. Frederick, ${ }^{*}$ M. T. Harper, ${ }^{*}$ H. Weeks, ${ }^{*}$ A. F. Branco, $†$ W. J. Price, $\ddagger$ \\ P. J. Moate,§ M. H. Deighton,§ S. R. O. Williams,§ M. Kindermann,\# and S. Duvalll \\ *Department of Animal Science, The Pennsylvania State University, University Park 16802 \\ †Departamento de Zootecnia, Universidade Estadual de Maringá, Brazil 87020-900 \\ $\ddagger$ Statistical Programs, College of Agricultural and Life Sciences, University of Idaho, Moscow 83844 \\ §Agriculture Research Division, Department of Economic Development Jobs Transport and Resources, Ellinbank Centre, Ellinbank 3821 , \\ Victoria, Australia \\ \#DSM Nutritional Products, Animal Nutrition \& Health, Basel CH-4002, Switzerland \\ IIDSM Nutritional Products France, Research Centre for Animal Nutrition and Health, Saint Louis Cedex, France 68305
}

\begin{abstract}
The objective of this study was to compare 2 commonly used techniques for measuring methane emissions from ruminant animals: the GreenFeed (GF) system and the sulfur hexafluoride $\left(\mathrm{SF}_{6}\right)$ technique. The study was part of a larger experiment in which a methane inhibitor, 3-nitrooxypropanol, fed at 4 application rates $(0,40,60$, and $80 \mathrm{mg} / \mathrm{kg}$ of feed dry matter) decreased enteric methane emission by an average of $30 \%$ (measured by both $\mathrm{GF}$ and $\mathrm{SF}_{6}$ ) in a 12-wk experiment with 48 lactating Holstein cows fed a total mixed ration. The larger experiment used a randomized block design and was conducted in 2 phases (February to May, phase 1, and June to August, phase 2), with 2 sets of 24 cows in each phase. Using both $\mathrm{GF}$ and $\mathrm{SF}_{6}$ techniques, methane emission data were collected simultaneously during experimental wk 2, 6, and 12 (phase 1) and 2, 9, and 12 (phase 2), which corresponded to a total of 6 sampling periods. During each sampling period, 8 spot samples of gas emissions (staggered over a 3-d period) were collected from each cow using GF, as well as $3 \times 24-\mathrm{h}$ collections using the $\mathrm{SF}_{6}$ technique. Methane emission data were averaged per cow for the statistical analysis. The mean methane emission was 373 (standard deviation $=96.3$ ) and 405 (standard deviation $=156) \mathrm{g} /$ cow per day for $\mathrm{GF}$ and $\mathrm{SF}_{6}$, respectively. Coefficients of variation for the 2 methods were 25.8 and $38.6 \%$, respectively; correlation and concordance between the 2 methods were 0.40 and 0.34 , respectively. The difference in methane emission between the 2 methods $\left(\mathrm{SF}_{6}\right.$ - GF) within treatment was from 46 to 144 and 24 to 27
\end{abstract}

\footnotetext{
Received January 14, 2016.

Accepted March 24, 2016.

${ }^{1}$ Corresponding author: anh13@psu.edu
}

g/d for phases 1 and 2, respectively. In the conditions of this experiment, the $\mathrm{SF}_{6}$ technique produced larger variability in methane emissions than the GF method. The overall difference between the 2 methods was on average about $8 \%$, but was not consistent over time, likely influenced by barn ventilation and background methane and $\mathrm{SF}_{6}$ concentrations.

Key words: methane, GreenFeed, sulfur hexafluoride, dairy cow

\section{Short Communication}

An important component of agricultural greenhouse gas (GHG) mitigation efforts is an accurate measurement of GHG emissions. Several procedures for measuring enteric methane emissions, 1 of the 2 most important GHG from animal agriculture, have been developed and used with variable success (Hammond et al., 2016). Among the most widely used procedures for measuring enteric methane are the sulfur hexafluoride $\left(\mathbf{S F}_{6}\right)$ tracer technique (Johnson et al., 1994) and, more recently, the GreenFeed system (GF; Zimmerman et al., 2011). Comparative studies reported relatively good agreement between $\mathrm{SF}_{6}$ or $\mathrm{GF}$ with respiration chamber data (Pinares-Patiño et al., 2011; Muñoz et al., 2012; Hammond et al., 2015). With respect to $\mathrm{SF}_{6}$, recent modifications to the technique decreased between-animal coefficients of variation $(\mathbf{C V})$ for methane yield (i.e., g/kg of DMI) to levels comparable to CV obtained using chambers (Deighton et al., 2014). Similarly, a study with growing dairy heifers concluded that estimates of methane emission generated by GF were comparable to values obtained by respiration chambers (Hammond et al., 2015). Those authors pointed out, however, that deployment of the GF units and replication must be carefully considered to ensure 
sufficient numbers of measurements are obtained. In a study with lactating dairy cows, methane emissions measured by GF were similar to values derived from respiration chambers and between-animal variability was also within the range observed in respiration chambers (Huhtanen et al., 2013). A direct comparison between $\mathrm{SF}_{6}$ and $\mathrm{GF}$ yielded larger $\mathrm{CV}$ for methane emissions and a poor relationship between methane emissions and $\mathrm{DMI}$ for the $\mathrm{SF}_{6}$ method in a naturally ventilated tiestall barn (Dorich et al., 2015). The objective of the current study was to compare enteric methane emission data from dairy cows derived simultaneously using GF and the $\mathrm{SF}_{6}$ technique, as modified by Deighton et al. (2014).

Animals involved in this experiment were cared for according to the guidelines of the Pennsylvania State University Animal Care and Use Committee. The committee reviewed and approved all procedures carried out in the study. The experiment was part of a larger randomized block design production experiment with 48 Holstein cows (details in Hristov et al., 2015a) and was conducted at the tiestall barn of the Pennsylvania State University's Dairy Research and Teaching Center. The experiment was conducted in 2 phases; the duration of each phase was $14 \mathrm{wk}$, including 2-wk covariate and 12 -wk experimental periods. The objective of the production experiment was to evaluate the effect of an inhibitor, 3-nitrooxypropanol (3NOP), on enteric methane emissions in lactating dairy cows. Cows were subjected to the following treatments: control (no additive) and 3NOP applied at 40 (low 3NOP), 60 (medium $3 \mathrm{NOP}$ ), and 80 (high $3 \mathrm{NOP}) \mathrm{mg} / \mathrm{kg}$ of feed DM. The diet was based on corn silage and alfalfa haylage, corn grain, whole roasted soybeans, a bakery by-product meal, and canola meal and was fed as a TMR (Hristov et al., 2015a) once daily with $3 \mathrm{NOP}$ or placebo premixes mixed in the TMR. The experiment was conducted in 2 phases (with 24 cows in each phase), with phase 1 from February to May 2014 and phase 2 from June to August 2014. Phase 2 began immediately following phase 1.

Enteric methane emissions were measured using GF (C-Lock Technology Inc., Rapid City, SD) and the $\mathrm{SF}_{6}$ technique (Deighton et al., 2014). Methane emission data were collected simultaneously from individual cows using both techniques during experimental wk 2, 6, and 12 (phase 1) and 2, 9, and 12 (phase 2), which corresponded to a total of 6 sampling periods. With GF, during each sampling period gas emission data were collected in 3 consecutive days starting at 0900, 1500, and $2100 \mathrm{~h}$ (sampling d 1), 0300, 1200, and 1700 $\mathrm{h}$ (sampling d 2), and 0000, and $0500 \mathrm{~h}$ (sampling d 3). This resulted in an average gas collection period of 40 $(8 \times 5) \mathrm{min} /$ cow per sampling period. Three GF units were used and all cows were sampled within $50 \mathrm{~min}$. Breath gas samples were collected for $5 \mathrm{~min}$ from each cow followed by a 2-min background gas sample collection. Calibration of the GF units was as described in Hristov et al. (2015b). Bait feed was offered at each of the 8 sampling events for a total of $4 \mathrm{~kg} /$ cow over $3 \mathrm{~d}$, which was approximately $5 \%$ of the total DMI for each cow during each 3-d sampling period. The bait feed used was a premix containing (as-is basis) $70 \%$ ground corn grain, $28 \%$ dried molasses, and $2 \%$ soybean oil.

For the $\mathrm{SF}_{6}$ method, permeation tubes containing $\mathrm{SF}_{6}$ were delivered into the reticulum of each cow using a bolus gun, $1 \mathrm{wk}$ before the first measurement occurred. The mean $( \pm \mathrm{SD})$ rate of $\mathrm{SF}_{6}$ release from permeation tubes used in the experiment was $4.38 \pm 0.261 \mathrm{mg} / \mathrm{d}$. The $\mathrm{SF}_{6}$ equipment, sample and canister processing, and analysis of the gas samples for methane and $\mathrm{SF}_{6}$ were as described in Deighton et al. (2014). Briefly, evacuated canisters were secured on the back of each cow using a harness. Breath gas was continuously collected through tubing extending to the nostrils of the cow. A total of 8 background gas collection canisters were placed on the back of 8 selected cows, evenly distributed in the barn. Background air samples were collected during each day of the $\mathrm{SF}_{6}$ measurements from the area on the back of the cows. Canisters were replaced every $24 \mathrm{~h}$ for an average sampling duration of $3.2 \pm 0.10 \mathrm{~d} / \mathrm{cow}$ and per sampling period. The average gas collection time was 4,620 $\mathrm{min} /$ cow per sampling period. An aliquot of the collected gas sample was extracted and analyzed for methane and $\mathrm{SF}_{6}$ using a gas chromatograph (Varian CP-3800, Varian Analytical Instruments, Walnut Creek, CA) as described in Williams et al. (2011) and Hristov et al. (2015a).

Methane emission data were averaged per cow and sampling period $\left(\mathrm{GF}=8\right.$ observations and $\mathrm{SF}_{6}=3.2$ observations per cow and sampling period) and the average values were used in the statistical analysis. Data were analyzed and outliers were removed based on an absolute studentized residual value $>3$. Descriptive statistics were computed and differences between average $\mathrm{SF}_{6}$ and $\mathrm{GF}$ methane emission data (i.e., $\mathrm{SF}_{6}$ - GF; g/d) for wk 2 and 12 only were analyzed using the GLIMMIX procedure of SAS (version 9.4; SAS Institute Inc., Cary, NC). The model contained block, treatment, sampling period, and block $\times$ treatment and sampling period $\times$ treatment interactions. Analyses were carried out separately for each phase and statistical differences were declared at $P \leq 0.05$. Additionally, Lin's concordance correlation coefficient (Lin, 1989) and Pearson correlation coefficient were calculated (all study weeks). All computations were done using SAS.

Descriptive statistics of the methane emission data are shown in Table 1. Overall, the mean methane emis- 
sion value was about $8 \%$ higher for $\mathrm{SF}_{6}$ compared with GF. The difference between the minimum and maximum values was considerably greater for $\mathrm{SF}_{6}(704 \mathrm{~g} / \mathrm{d})$ than GF $(456 \mathrm{~g} / \mathrm{d})$. The $\mathrm{CV}$ and standard deviation were also greater for $\mathrm{SF}_{6}$ than GF. Similar trends were observed for both experimental phases (winter and summer), except $\mathrm{SF}_{6}$ emission values were higher in phase 1 and lower in phase 2 compared with GF values. The CV for GF was similar between phase 1 and 2, but was considerably greater in phase 2 compared with phase 1 for $\mathrm{SF}_{6}$. The Pearson and concordance correlation coefficients for methane yield for the 2 methods were low, at 0.40 and 0.34 , respectively.

Statistical analysis of the difference in methane emission between $\mathrm{SF}_{6}$ and GF is shown in Table 2. The difference between the 2 methods appeared to decrease with increasing the application rate of $3 \mathrm{NOP}$, with the

Table 1. Descriptive statistics of enteric methane emissions from dairy cows measured using GreenFeed (GF) and the sulfur hexafluoride $\left(\mathrm{SF}_{6}\right)$ techniques $^{1}$

\begin{tabular}{|c|c|c|}
\hline \multirow[b]{2}{*}{ Item } & \multicolumn{2}{|c|}{ Technique } \\
\hline & GF & $\mathrm{SF}_{6}$ \\
\hline \multicolumn{3}{|c|}{ Overall methane emissions, $\mathrm{g} / \mathrm{d}$} \\
\hline Cows, $\mathrm{n}^{2}$ & 143 & 141 \\
\hline Mean $^{3}$ & 373 & 405 \\
\hline Min & 187 & 104 \\
\hline $\operatorname{Max}$ & 643 & 808 \\
\hline Lower $\mathrm{CL}^{4}$ & 357 & 379 \\
\hline Upper CL & 389 & 431 \\
\hline $\mathrm{CV}, \%$ & 25.8 & 38.6 \\
\hline $\mathrm{SD}$ & 96.3 & 156 \\
\hline \multicolumn{3}{|c|}{ Experimental phase 1 (winter) ${ }^{5}$} \\
\hline Cows, $\mathrm{n}$ & 72 & 71 \\
\hline Mean & 379 & 470 \\
\hline Min & 198 & 201 \\
\hline Max & 643 & 808 \\
\hline Lower CL & 357 & 435 \\
\hline Upper CL & 401 & 505 \\
\hline $\mathrm{CV}, \%$ & 24.9 & 31.5 \\
\hline $\mathrm{SD}$ & 94.4 & 148 \\
\hline \multicolumn{3}{|c|}{ Experimental phase 2 (summer) } \\
\hline Cows, $\mathrm{n}$ & 71 & 70 \\
\hline Mean & 368 & 339 \\
\hline Minimum & 188 & 104 \\
\hline Maximum & 614 & 762 \\
\hline Lower CL & 344 & 306 \\
\hline Upper CL & 391 & 371 \\
\hline $\mathrm{CV}, \%$ & 26.8 & 40.2 \\
\hline $\mathrm{SD}$ & 98.6 & 136 \\
\hline
\end{tabular}

${ }^{1}$ Data from Hristov et al. (2015a).

${ }^{2} \mathrm{n}=$ number of individual cow measurements: phase $1=24$ cows measured in experimental wk 2,6 , and 12 ; phase $2=24$ cows measured in experimental wk 2,9 , and 12 . One cow was not sampled with GreenFeed in phase 2. Outlier analysis removed 1 value in phase 1 and 2 values in phase 2 from the $\mathrm{SF}_{6}$ data.

${ }^{3}$ Mean emission values (g/d) across treatments (see Table 2).

${ }^{4} 95 \%$ confidence limit for the mean.

${ }^{5}$ Experimental phase 1 was from February to May 2014; experimental phase 2 was from June to August 2014.
Table 2. Difference between enteric methane emissions in dairy cows measured using GreenFeed $(\mathrm{GF})$ and the sulfur hexafluoride $\left(\mathrm{SF}_{6}\right)$ techniques $^{1}$

\begin{tabular}{lccc}
\hline Item $^{2}$ & Difference $^{3}$ & SEM & $P$-value \\
\hline Experimental phase 1 (winter) & & \\
$\quad$ Control & 144 & 20.7 & $<0.001$ \\
Low 3NOP & 107 & 21.8 & $<0.001$ \\
Medium 3NOP & 72 & 20.7 & 0.001 \\
High 3NOP & 46 & 20.7 & 0.03 \\
Overall, phase 1 & 92 & 10.5 & $<0.001$ \\
Experimental phase 2 (summer) & & & \\
Control & -62 & 27.0 & 0.03 \\
Low 3NOP & 0.6 & 24.2 & 0.98 \\
Medium 3NOP & -13 & 24.2 & 0.58 \\
High 3NOP & -39 & 25.3 & 0.13 \\
Overall, phase 2 & -28 & 12.6 & 0.03 \\
Overall, phase 1 and 2 & 19 & 9.2 & 0.04 \\
\hline
\end{tabular}

${ }^{1}$ Data from Hristov et al. (2015a).

${ }^{2} \mathrm{Control}=0 \mathrm{mg} / \mathrm{kg}$ of 3-nitrooxypropanol (3NOP); Low $3 \mathrm{NOP}=40$ $\mathrm{mg} / \mathrm{kg}$ of $3 \mathrm{NOP}$; Medium $3 \mathrm{NOP}=60 \mathrm{mg} / \mathrm{kg}$ of $3 \mathrm{NOP}$; High $3 \mathrm{NOP}=$ $80 \mathrm{mg} / \mathrm{kg}$ of $3 \mathrm{NOP}$ (dietary DM basis).

${ }^{3}$ Difference $=\mathrm{SF}_{6}-\mathrm{GF}$ (g of methane/d). In both phase 1 and 2, methane emission data for 2 sampling periods (i.e., experimental wk 2 and 12) were compared; $\mathrm{n}=47$ ( $\mathrm{n}$ represents the number of observations used in the statistical analysis). Data are LSM.

${ }^{4} P$-value for the difference in methane emission $(\mathrm{g} / \mathrm{d})$ between $\mathrm{SF}_{6}$ and GF.

${ }^{5}$ Experimental phase 1 was from February to May 2014; experimental phase 2 was from June to August 2014.

largest difference being for the control cows. In phase 1, determinations of methane emission by the $\mathrm{SF}_{6}$ method were on average about $92 \mathrm{~g} / \mathrm{d}$ greater $(P<0.001)$ than estimates derived using GF for all treatments. We observed no difference between the 2 methods for all 3 NOP levels in phase 2 , but for the control cows GF emission values were higher $(P=0.03)$ than those measured using $\mathrm{SF}_{6}$. The overall difference between the methods in phase 2 was $28 \mathrm{~g} / \mathrm{d}(P=0.03)$. Across experimental phases, methane emission values were, on average, $19 \mathrm{~g} / \mathrm{d}$ greater $(P=0.04)$ for $\mathrm{SF}_{6}$ than GF. It is noted that DMI of the cows was not affected $(P \geq$ $0.49)$ by treatment in both phase $1(28.0 \pm 0.61)$ and $2(27.6 \pm 0.69 \mathrm{~kg} / \mathrm{d})$ of the experiment (Hristov et al., 2015a).

The difference between methods in phase 1 versus 2 was remarkable. Phase 1 was conducted in colder weather (February to May), whereas phase 2 was conducted during the summer months (June to August). The average temperatures in the State College, Pennsylvania, area during the 2 experimental phases were $5.1^{\circ} \mathrm{C}$ (minimum $=-9.3^{\circ} \mathrm{C}$, maximum $=19.0^{\circ} \mathrm{C}$ ) and $20.9^{\circ} \mathrm{C}$ (minimum $=10.2^{\circ} \mathrm{C}$, maximum $=31.1^{\circ} \mathrm{C}$ ), respectively. The tiestall barn where the experiment was conducted was ventilated through tunnel ventilation controlled by a thermostat set at $4.4^{\circ} \mathrm{C}$. In phase 1 , barn ventilation was only sporadically turned on during the 3 to $4 \mathrm{~d}$ of $\mathrm{SF}_{6}$ measurements, whereas ventila- 
tion was manually turned and kept on during each GF measurement period $(8 \times 50 \mathrm{~min}$ in $3 \mathrm{~d})$. Maintaining continuous ventilation in phase 1 was not possible due to possibility of water freezing in the pipelines. In contrast, ventilation was continuously on during phase 2 due to the high ambient temperature. As a result, background air concentrations of methane and $\mathrm{SF}_{6}$ in the barn were considerably higher during phase $1 \mathrm{com}-$ pared with phase 2. For example, the average methane concentrations in the background air samples were 33 \pm 23.6 versus $9.7 \pm 1.7 \mathrm{ppm}$ in phase 1 and 2 , respectively. The average $\mathrm{SF}_{6}$ background concentrations were $35 \pm 14.0$ versus $23 \pm 1.8 \mathrm{ppt}$, respectively. For comparison, the average methane concentrations in the animal samples ( $\mathrm{SF}_{6}$ technique) were $87 \pm 24.2$ and 46 $\pm 8.4 \mathrm{ppm}$ during phase 1 and 2 , respectively, whereas the corresponding average $\mathrm{SF}_{6}$ concentrations were 94 \pm 27.3 and $72 \pm 5.7$ ppt. Thus, the high background air concentrations of methane and $\mathrm{SF}_{6}$ in phase 1 versus 2 may explain the discrepancies in methane emission measurements between experimental phases using the 2 techniques.

In recent years, several studies compared GF and $\mathrm{SF}_{6}$ methane emission measurements to chamber data. Dorich et al. (2015) reported similar methane emissions from lactating dairy cows using $\mathrm{GF}$ and $\mathrm{SF}_{6}$, but the $\mathrm{SF}_{6}$ technique produced higher variability in the relationship between methane and DMI compared with GF. Similar to our study, those authors attributed the higher variability in the $\mathrm{SF}_{6}$ measurements to the high concentration of background gases as a result of poor barn ventilation. The importance of $\mathrm{SF}_{6}$ concentrations in background air when using the $\mathrm{SF}_{6}$ technique has been discussed by Williams et al. (2011) and Lassey (2013). The latter author, for example, emphasized the need for deployment of multiple background samplers to account for methane and $\mathrm{SF}_{6}$ concentration gradients, the importance of location of the background samplers, and the need for building ventilation when the technique is used indoor. It was recently recommended that background concentrations of $\mathrm{SF}_{6}$ should be $<10 \mathrm{ppt}$ and $<10 \%$ of the concentrations in the breath sample (Berndt et al., 2014). This ratio was not achieved in the current experiment.

Hammond et al. (2015) found relatively good agreement between emission data using GF and respiration chambers, but concordance between the 2 methods was poor. Those authors also investigated $\mathrm{SF}_{6}$ and, similar to data from phase 1 of the current experiment, reported generally lower emission values compared with GF. Hammond et al. (2015) concluded, however, that GF was unable to detect significant treatment and individual animal differences in methane emissions that were detected using respiration chambers or the $\mathrm{SF}_{6}$ technique. As discussed by Hristov et al. (2015b) and Hammond et al. (2016), optimal use of GF is when timing of the sampling events is controlled by the investigator, such as in a tiestall barn. Velazco et al. (2016) compared GF and respiration chamber methane emission measurements and concluded that both methods produced similar results.

Several factors are important when methane emissions are measured using spot sampling, such as GF. Waghorn et al. (2015) pointed out the importance of the number of GF visits per cow to derive reliable methane emission estimates. Cottle et al. (2015) concluded that spot measurements of enteric emissions using GF can be used to determine absolute methane emission, but the number of animals and samples are larger than are needed when day-long measures are made (such as with respiration chambers). GreenFeed visits were controlled by the research team in the current experiment, which ensured enteric methane was sampled throughout the 24-h feeding cycle.

Overall, in the conditions of this experiment, the $\mathrm{SF}_{6}$ technique produced larger variability in methane emissions than the GF method. Correlation and concordance between the 2 methods were relatively low. The difference between the 2 methods was not consistent over time, likely influenced by barn ventilation and background methane and $\mathrm{SF}_{6}$ concentrations. We concluded that the $\mathrm{SF}_{6}$ technique should be used in well-ventilated buildings or outdoors and data generated with the technique should be interpreted with caution when background methane and $\mathrm{SF}_{6}$ concentrations are high.

\section{ACKNOWLEDGMENTS}

The authors thank the staff of the Department of Animal Science, Pennsylvania State University's Dairy Center for their conscientious care of the experimental cows. The study was partially funded by DSM Nutritional Products (Basel, Switzerland).

\section{REFERENCES}

Berndt, A., T. M. Boland, M. H. Deighton, J. I. Gere, C. Grainger, R. S. Hegarty, A. D. Iwaasa, J. P. Koolaard, K. R. Lassey, D. Luo, R. J. Martin, C. Martin, P. J. Moate, G. Molano, C. Pinares-Patiño, B. E. Ribaux, N. M. Swainson, G. C. Waghorn, and S. R. O. Williams. 2014. Guidelines for use of sulphur hexafluoride $\left(\mathrm{SF}_{6}\right)$ tracer technique to measure enteric methane emissions from ruminants. Page 166. M. G. Lambert, ed. New Zealand Agricultural Greenhouse Gas Research Centre, New Zealand.

Cottle, D. J., J. Velazco, R. S. Hegarty, and D. G. Mayer. 2015. Estimating daily methane production in individual cattle with irregular feed intake patterns from short-term methane emission measurements. Animal 9:1949-1957. http://dx.doi.org/10.1017/ S1751731115001676. 
Deighton, M. H., S. R. O. Williams, M. C. Hannah, R. J. Eckard, T. M. Boland, W. J. Wales, and P. J. Moate. 2014. A modified sulphur hexafluoride tracer technique enables accurate determination of enteric methane emissions from ruminants. Anim. Feed Sci. Technol. 197:47-63.

Dorich, C. D., R. K. Varner, A. B. D. Pereira, R. Martineau, K. J. Soder, and A. F. Brito. 2015. Short communication: Use of a portable automated open-circuit gas quantification system and the sulfur hexafluoride tracer technique for measuring enteric methane emissions in Holstein cows fed ad libitum or restricted. J. Dairy Sci. 98:2676-2681.

Hammond, K. J., L. A. Crompton, A. Bannink, J. Dijkstra, D. R. Yáñez-Ruiz, P. O'Kiely, E. Kebreab, M. A. Eugenè, Z. Yu, K. J. Shingfield, A. Schwarm, A. N. Hristov, and C. K. Reynolds. 2016. Review: Suitability of current in vivo measurement techniques to meet specific objectives for accurately quantifying enteric methane emissions from ruminants. Anim. Feed Sci. Technol. submitted.

Hammond, K. J., D. J. Humphries, L. A. Crompton, C. Green, and C. K. Reynolds. 2015. Methane emissions from cattle: Estimates from short-term measurements using a GreenFeed system compared with measurements obtained using respiration chambers or Sulphur hexafluoride tracer. Anim. Feed Sci. Technol. 203:41-52.

Hristov, A. N., J. Oh, F. Giallongo, T. Frederick, M. Harper, H. Weeks, A. Branco, P. Moate, M. Deighton, R. Williams, M. Kindermann, and S. Duval. 2015a. An inhibitor persistently decreased enteric methane emission from dairy cows with no negative effect on milk production. Proc. Natl. Acad. Sci. USA 112:10663-10668.

Hristov, A. N., J. Oh, F. Giallongo, T. Frederick, H. Weeks, P. R Zimmerman, R. A. Hristova, S. R. Zimmerman, and A. F. Branco. 2015b. The use of an automated system (GreenFeed) to monitor enteric methane and carbon dioxide emissions from ruminant animals. J. Vis. Exp. 103:e52904. http://dx.doi.org/10.3791/52904.

Huhtanen, P., S. J. Krizsan, M. Hetta, H. Gidlund, and E. H. Cabezas Garcia. 2013. Repeatability and between cow variability of enteric $\mathrm{CH}_{4}$ and total $\mathrm{CO}_{2}$ emissions. Adv. Anim. Biosci. 4:588.
Johnson, K., M. Huyler, H. Westberg, B. Lamb, and P. Zimmerman. 1994. Measurement of methane emissions from ruminant livestock using a $\mathrm{SF}_{6}$ tracer technique. Environ. Sci. Technol. 28:359-362.

Lassey, K. R. 2013. On the importance of background sampling in applications of the $\mathrm{SF}_{6}$ tracer technique to determine ruminant methane emissions. Anim. Feed Sci. Technol. 180:115-120.

Lin, L. I. 1989. A concordance correlation coefficient to evaluate reproducibility. Biometrics 45:255-268.

Muñoz, C., T. Yan, D. A. Wills, S. Murray, and A. W. Gordon. 2012 Comparison of the sulfur hexafluoride tracer and respiration chamber techniques for estimating methane emissions and correction for rectum methane output from dairy cows. J. Dairy Sci. 95:31393148 .

Pinares-Patiño, C. S., K. R. Lassey, R. J. Martin, G. Molano, M. Fernandez, S. MacLean, E. Sandoval, D. Luo, and H. Clark. 2011. Assessment of the sulphur hexafluoride $\left(\mathrm{SF}_{6}\right)$ tracer technique using respiration chambers for estimation of methane emissions from sheep. Anim. Feed Sci. Technol. 166-167:201-209.

Velazco, J. I., D. G. Mayer, S. Zimmerman, and R. S. Hegarty. 2016. Use of short-term breath measures to estimate daily methane production by cattle. Animal 10:25-33.

Waghorn, G., A. Jonker, and K. MacDonald. 2015. Measuring methane from grazing dairy cows using GreenFeed. Anim. Prod. Sci. In press.

Williams, S. R. O., P. J. Moate, M. C. Hannah, B. E. Ribaux, W. J. Wales, and R. J. Eckard. 2011. Background matters with the $\mathrm{SF}_{6}$ tracer method for estimating enteric methane emissions from dairy cows: A critical evaluation of the $\mathrm{SF}_{6}$ procedure. Anim. Feed Sci. Technol. 170:265-276.

Zimmerman, P., S. Zimmerman, S. Utsumi, and D. Beede. 2011. Development of a user-friendly online system to quantitatively measure metabolic gas fluxes from ruminants. J. Dairy Sci. 94(E-Suppl. 1):760. (Abstr.) 